\title{
EUROPEAN
}

DOI: 10.1515/ep-2015-0001

Marcin Gołaszewski*
Andrzej Frycz Modrzewski Kraków University
Paweł Zając
Andrzej Frycz Modrzewski Kraków University
Jan Widacki
Andrzej Frycz Modrzewski Kraków University
Poland

\section{Thermal Vision as a Method of Detection of Deception: A Review of experiences**}

Key Words: thermal vision, detection of deception, instrumental detection of deception, thermal vision and detection of deception

\section{Introduction}

Turning pale or red in the face, besides expressive movements (mimic and pantomimic) belonged to the earliest observed symptoms of emotions, which sometimes were even directly treated as symptoms of the lie (Trovillio 1938/1939, Eysenck 1971). Thanks to experimental psychology and physiology, since the end of the 19th and early 20th centuries they have been known to result from changes in the blood supply to the face related to the functioning of the circulatory system, movement of

\footnotetext{
*marcin.golaszewski@wp.pl

${ }^{* *}$ Project DEC-2013/11/B/H55/03856 funded by National Science Centre.
} 
muscles, and chemical changes in the blood and its energetic value (dependent on the amount of oxygen, catecholamines, etc.), a knowledge embracing also the fact that physiological changes accompanying emotions encompass the entire organism and are clearly correlated. Thus, theoretically, it suffices to observe any fragment of the organism to detect emotions, and the number of physiological correlates of emotions, if not unlimited, is certainly very large. Some of them are clearly visible for an external observer (for example, the expressive movements, blanching, blushing, tremors, etc.). Others can be observed only with specialist devices, with polygraph being the best known among them.

The following physiological correlates of emotions are usually selected for observation and examination (see e.g. Hilgard 1972):

changes in the operation of the heart and the entire circulatory system (blood pressure and heart rate changes, changes of electric phenomena in the muscles of the heart)

- changes in the operation of the respiratory system (changes in the rate of breathing cycles, volume of inspired and expired air)

- changes in electric conductivity (galvanic skin response, GSR)

- changes in muscle tension

- changes in organ volumes (plethysmographic reaction)

- changes in pilomotor reaction

- changes in pupil dilation ('pupillary light reflex')

- body temperature changes.

The last can successfully be observed and registered by a thermal vision camera.

Thermal vision, also known as thermography, has become one of the most popular and frequently applied methods of imaging heat radiation emitted by physical objects, as it allows remote observation, without the need of intervention into the examined object. Industry, construction, aviation, and medicine are the special areas that can be enumerated within the broad spectre of current practical uses for a thermal vision camera. Thermal imaging is used in medicine for diagnostic reasons wherever a non-invasive measurement of body temperature changes is convenient (Memarian et al. 2009; Bauer, Dereń 2014). As a method of observation, measurement, and recording of body (especially face) temperature changes, thermal vision can also be used in experimental psychology, psychophysiology, and their counterparts among forensic sciences. In this last field, its potential use for lie detection is particularly significant.

Thanks to the application of thermal imaging in mid-wavelength infrared (MWIR), a thermal vision camera is capable of detecting temperature changes of specific frag- 
ments of the human body, resulting among others from the emergence of emotions that may be related to lying. In this context, thermal vision is an attractive direction in scientific research, as its practical application can be examined in three variants:

a) instead of a polygraph, independently - when time matters, or at least initial tests must be performed on a mass scale - and/or remotely (contact-free, non-invasively), without the subjects being aware and without the need to employ highly qualified and/or trained personnel (Pavlidis et al., 2002). One of the options to use thermal vision in this way is to set up a system that would collect certain data (e.g. biometric) to allow detection and estimation of the level of threat from various people. It would be possible for example to expand the already operating TOLIS (Traveler On-Line Information System) system, which among others, contains information about the manner of payment for the passenger's ticket: cash or card, with the first one considered more risky, and awarding a greater number of risk points to the traveller (Pavlidis, Levine 2002a)

b) combined with a polygraph: for possible increasing the precision of (stationary) examinations conducted by adding on top of the traditionally recorded changes (breathing functions, GSR changes, blood circulation changes) those of facial temperature

c) combined with other technical means capable of remote registration of other physiological correlates of emotions and memory traces (e.g., changes in the voice and the pupillary light reflex) even without the subject being aware.

\section{Symptoms of deception in thermal imaging of the face}

Methods that allow high-probability identification of people in whom certain reactions of the organism, attesting to the deception in speech are present are generally known. Such observations may be made particularly through polygraph examination, which typically registers changes in the blood pressure and heart rate, breathing cycle, and electrodermal reactions. Highly encouraging are also the results of experiments conducted by certain researchers and aimed at detection of deception by registering and analysing the temperature of specific fragments of the face under the impact of emotions accompanying lie.

Experiments with a thermal vision camera conducted in the late 1990s brought a discovery that an instantaneous increase of temperature in the periorbital region (see Fig. 1) occurs as a reaction to an external startling stimulus, which results from increased blood flow rate around the eyes (Pavlidis et al. 2000; Levine et al. 2001). It was established that the discovery can be used for detection of deception, as the 
blood flow rate accounts for a similar type of physiological data as acquired from the sensors that are part of a traditional polygraph machine (Pavlidis, Levine 2002b).

Fig. 1. Thermal images of the face for a subject before (a) and $300 \mathrm{msec}$ after (b) an instantaneous startle. (Arrows indicate local warming in the periorbital region.)
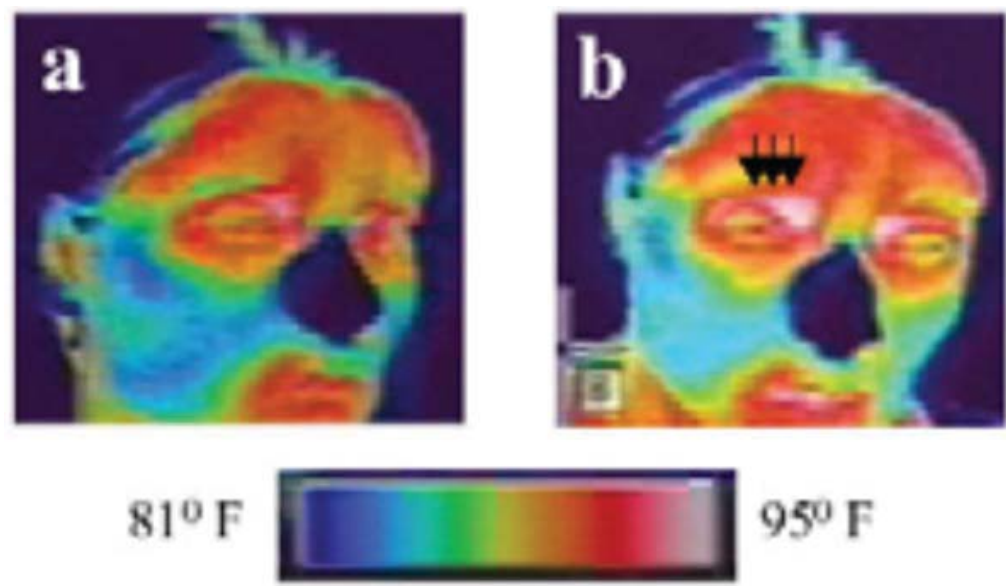

Source: I. Pavlidis, J. Levine, P. Baukol (2000), Thermal imaging for anxiety detection, Proceedings 2000 IEEE Workshop on Computer Vision Beyond the Visible Spectrum: Methods and Applications, Hilton Head Island, SC, 16 June 2000, p. 107.

Results of the experimental research conducted by members of the Institute of Electrical and Electronic Engineers (IEEE) show that monitoring of periorbital (P), supraorbital $(\mathrm{S})$ and maxillary $(\mathrm{M})$ regions of the face has a similar diagnostic value as galvanic skin response (GSR; Shastri et al. 2009). The phasic component of the periorbital signal is in phase with the GSR signal. The tempo of such changes is different (GSR reactions are more rapid) yet they start at a similar point in time and share a similar trend. Moreover, a phase shift of $180^{\circ}$ was observed on the charts between the phasic elements of the curves representing maxillary and periorbital region signals (see: Fig. 2). The reason for this is the link between the signal from the periorbital region and the supply of blood to the orbital muscle which results in increased temperature in the area during stimulation. In turn the signal from the maxillary area depends on the activity of sweat glands, which leads to an inverse effect, that is lowering of temperature. 
Fig. 2. Phasic components of thermal and GSR signals for subject Sub1.

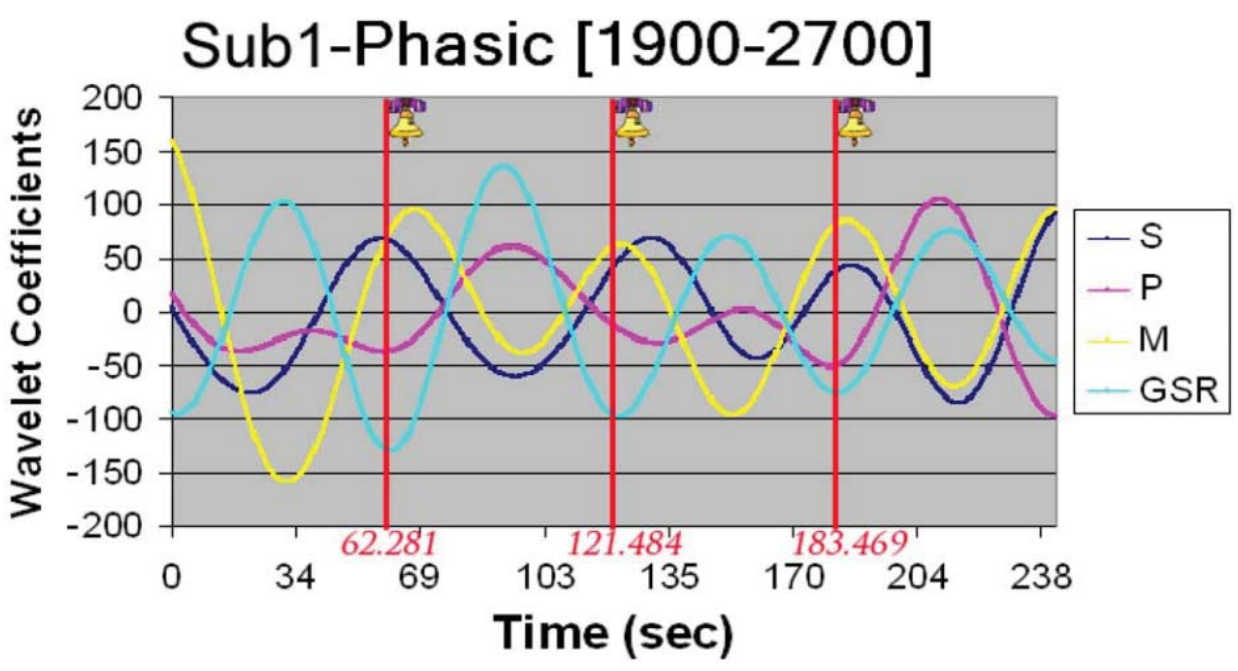

Source: D. Shastri, A. Merla, P. Tsiamyrtzi, I. Pavlidis (2009), Imaging Facial Signs of Neurophysiological Responses, IEEE Transactions on Biomedical Engineering, Vol. 56, No. 2, p. 482.

In an article entitled The mental nose: thermography and the Pinocchio effect, E. Salazar Lopez, E. Dominguez, J. de la Fuente, A. Meins, O. Iborra, M.A. RodriguezArtacho, and E. Gomez Milan described the potential of using thermal imaging to observe changes of temperature in specific areas of the face as resulting from emotions caused by activities that require mental effort and also linked to lying. The analysis covered readings from the areas around the eyes, corners of the eyes, and the region around the nose. The study group was composed of 20 people. The experiment consisted in performance of three tasks. The task concerning phobias and fears aimed at observation of temperature changes in specific fragments of the face under the impact of emotions emerging while watching images with pictures of drug addicts, spiders, cadavers, and neutral objects. The study group consisted of people suffering from arachnophobia, aichmophobia, necrophobia as well as people suffering from none of the phobias mentioned above. The task related to a mental effort consisted in planning a route in a zoo so as to follow a specific strategy and visit 6 out of 12 places (the results of the Aldeman's Behavioral Assessment of Dysexecutive Syndrome (BADS) were used). In turn, the task related to lie detection was divided into two types of tests (depending on the level of psychological burden). Participants of the examination employing a high level of psychological burden were taken to a laboratory. There, they were informed that the visit was secret and they could not discuss it with anyone. Later, they were given the task to devise an alibi and call 
a friend or acquaintance. During the telephone conversation, 10 people were to tell the truth, and 10 people were to lie about the course of the day. Participants of the examination with low psychological burden were to provide answers to 12 questions (10 people were to tell the truth and only truth, while the remaining 10 were to provide deceptive answers to 4 questions). The results of the examination concerning lie detection proved that during an exercise requiring a high psychological effort, in 7 in 10 people asked to lie about the course of the day experienced an increase of temperature around the nose by $1.3^{\circ} \mathrm{C}$ and by $0.9^{\circ} \mathrm{C}$ in the region of the forehead was recorded while they were planning the conversation, i.e. building their alibis. In turn, in the case of lying during the telephone conversation, a drop of temperature by $1.1^{\circ} \mathrm{C}$ was recorded around the nose in $80 \%$ of participants. To compare, no changes in face temperature were recorded at all in the group telling the truth (Salazar et al. 2012).

I. Pavlidis and J. Levine transformed the raw thermal data into data concerning the blood flow rate by using a thermodynamic model that assumes that the blood flow rate is conversely proportional to the square of skin temperature deviation from core temperature of the human body. An stumbling block in this model is the impact of propagating heat generated by post-prandial metabolism, which provides a disruptive factor: the reason why the subject should fast for a number of hours before the examination. Cooperating with psychologists from the US Department of Defence Polygraph Institute (DoDPI), the two scientists conducted an experiment with 32 subjects. Some of them were to perform a mock crime (jabbing a mannequin with a screwdriver and stealing \$20), while the others had no connection to the event. Subsequently the whole group were subjected to a polygraph examination using federal ZCT and GKT tests. Pavlidis and Levine's method consisted of three stages: image acquisition, physiological correlation (calculation of blood flow rate), and standard classification - final opinions concerning truthfulness of the subjects' answers (Pavlidis, Levine 2001). Images of the subjects' faces were recorded while they were answering questions asked during a polygraph examination. A cooled mid-infrared camera operating in mid-wavelength infrared, with sensitivity of $0.025^{\circ} \mathrm{C}$ was used. The temperature scope was set from $29^{\circ} \mathrm{C}$ to $38^{\circ} \mathrm{C}$ which corresponds to the external temperature of human face. To eliminate the impact of lighting on the measurements, the examination was conducted in a darkened room. In the case of the ZCT test, the average length of recording was 300 frames, at the speed of 30 frames per second (fps), and for the GKT was half as short. Two regions of the face taken into account in the analysis - the area around the eyes and the forehead of the subject - were defined on the first recorded frame. This followed the assumption that the object of the study is relatively stationary, as 
in this case movement is a disruptive factor. After the exclusion of materials that could not be appropriately assessed for a variety of reasons, data of 18 subjects were considered analysis-worthy, with most adequate being the answers to the question no. 10 from the federal ZCT sequence. The 'forehead' signals proved insufficient to distinguish truthful from deceptive subjects. The case was otherwise with the signals from the area around the eyes. They provided the grounds to state that the reaction to the question occurs in two stages. While the question is being answered, the curve defining the blood flow rate in time rises slightly in the case of all the subjects. Not much changes in the second phase if the subject answers truthfully. The difference is, however, visible in the case of people providing deceptive answers: in their case the curve grows rapidly, as an expression of increased blood circulation around the eyes under the impact of anxiety. The authors explain that this data is perfect for a polygraph examination, because (like in the case of the polygraph), the interesting element is the relative speed of the rising of the curves (see Fig. 3).

Fig. 3. Normalised lines characterising the slopes of the average periorbital blood flow rate in time $T$. The slope of the answer session appears quite steep.
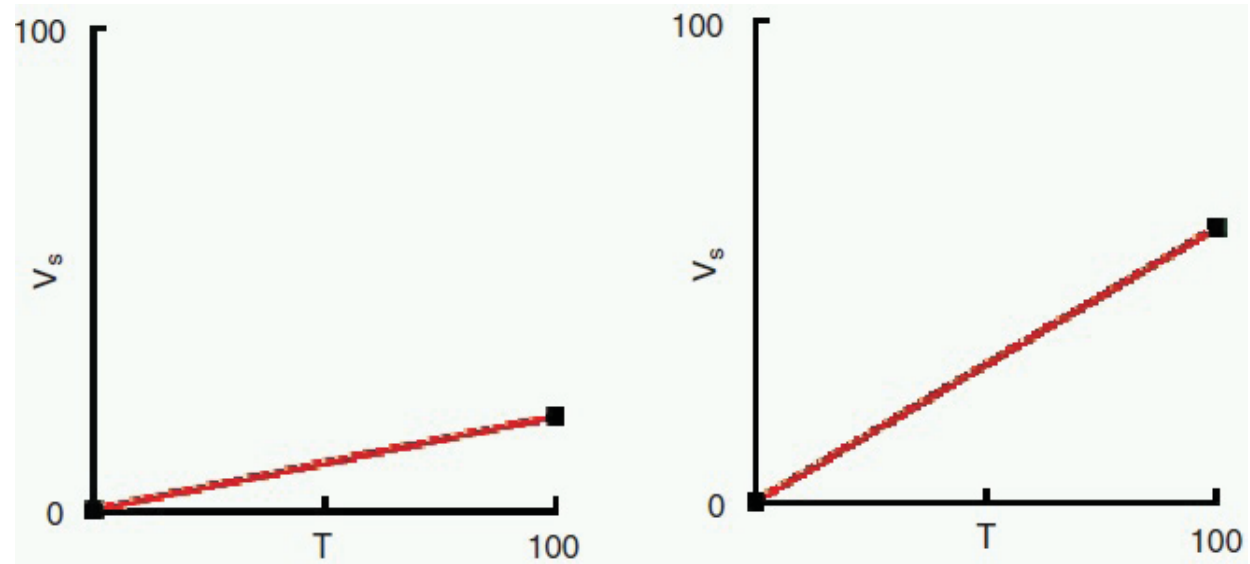

Source: I. Pavlidis, J. Levine (2002b), Thermal Image Analysis for Polygraph Testing, IEEE Engineering in Medicine and Biology, Vol. 21, No. 6, p. 61.

The definition of threshold values makes use of the so-called Otsu algorithm. If the slope product of the curve was lower than the threshold, the subject was classified as truthful, was greater - deception was concluded. The value of deviation was the angle between the curve and the horizontal line of the chart defining time following 
the answer (151 frames). The threshold used for the binary honest/deceptive classification was set at $67^{\circ}$. Finally, the proportion of correct decisions while analysing facial temperature changes amounted to $84 \%$, and was insignificantly different from the correctness level obtained in the experiment through the traditional method of polygraph chart analysis (78\%). Pavlidis and Levine recognised that further studies should among others focus on the improvement of the assumed model of heat propagation by estimation of the factor related to the heat produced through metabolism, design of an algorithm to allow tracing of head movements during the test, definition of a mesh of specific critical points on the face where blood flow rate will be monitored.

An experiment concerning the possibility of combining thermal imaging with a polygraph examination to detect deception was conducted by D.A. Pollina and A.H. Ryan of DoDPI. To test the hypothesis that temperatures of specific areas in the face change while answering relevant and comparison questions related to deception, 14 regions of the face were selected for analysis. It comprised readings from around the mouth, ears, neck, and eyes, with the maximum values of temperature recorded and collected bilaterally (e.g. from both the ears). The average from the pair of readings was used for statistical analysis. The study group consisted of 16 people. Before starting the test, participants were divided into two subgroups. The first subgroup of 'the innocent' was told that - because they were 'innocent' - they were to answer questions truthfully. In turn, the task of the other subgroup was to commit a mock crime, and later to lie about it during a polygraph examination, making use of a Zone Comparison Test (ZCT) with two repetitions. A recording with an infrared camera $\left(256 \times 256 \mathrm{FPA}\right.$, sensitivity $\left.<0.1^{\circ} \mathrm{C}\right)$ began at the moment when relevant and comparison questions were asked. A model of binary logistic regression was used in the examination. The following correlations were tested: thermal imaging - breath, thermal imaging - GSR, and thermal imaging - blood pressure. The highest correlation was proved for the thermal imaging - blood pressure pair. The results of the test proved that the regions around the nose and eyes demonstrate highest temperature fluctuations connected directly to lying. The authors believe that these regions can be considered the relatively most efficient deception predictors, and the most precise overall results were acquired in combination with a traditional polygraph examination (Pollina, Ryan 2004). 
Table 1. Results of the experiment conducted, denoting the number of correct indications (hits) while using polygraph, and combined examination: polygraph with thermal imaging of the region around eyes and nose.

\begin{tabular}{|l|l|l|l|l|l|l|l|l|l|l|l|l|}
\hline $\begin{array}{l}\text { Cutoff } \\
\text { Score }\end{array}$ & \multicolumn{4}{l|}{$\begin{array}{l}\text { Polygraph } \\
\text { Measures }\end{array}$} & \multicolumn{4}{l|}{$\begin{array}{l}\text { Polygraph \& SST: } \\
\text { Eye }\end{array}$} & \multicolumn{3}{l|}{$\begin{array}{l}\text { Polygraph \& SST: } \\
\text { Nose }\end{array}$} & \multicolumn{3}{l|}{$\begin{array}{l}\text { Polygraph \& SST: } \\
\text { Eye, Nose }\end{array}$} \\
\hline & Hit & Miss & Inc. & Hit & Miss & Inc. & Hit & Miss & Inc. & Hit & Miss & Inc. \\
\hline $.5 / .5$ & 16 & 8 & 0 & 19 & 5 & 0 & 21 & 3 & 0 & 20 & 4 & 0 \\
\hline $.6 / .4$ & 16 & 4 & 4 & 17 & 2 & 5 & 16 & 3 & 5 & 18 & 3 & 3 \\
\hline $.7 / .3$ & 15 & 2 & 7 & 15 & 2 & 7 & 14 & 1 & 9 & 16 & 2 & 6 \\
\hline $.8 / .2$ & 14 & 0 & 10 & 12 & 2 & 10 & 12 & 1 & 11 & 15 & 0 & 9 \\
\hline $.9 / .1$ & 7 & 0 & 17 & 11 & 0 & 13 & 12 & 0 & 12 & 12 & 0 & 12 \\
\hline
\end{tabular}

Source: D.A. Pollina, A.H. Ryan (2004), The relationship between facial skin surface temperature reactivity and traditional polygraph measures used in the psychophysiological detection of deception: a preliminary investigation, Polygraph, Vol. 33 (3), p. 150.

The DoDPI scientists conducted also two other experiments with thermal vision (Pollina et al. 2006). In both cases, infrared cameras were used during a CIT (Concealed Information Test) polygraph examination. Participating in the first experiment were 30 people, of which number records from the examination of 15 participants could be used finally. The appropriate frame with the beginning of the verbal answer of the subject was selected visually and included into the analysis of three frames distant $0.33 \mathrm{~s}$ from one another, and preceding and following the given answer. For each recorded frame, the maximum and minimum temperature of individual pixels was recorded for the analysed timeframe. It was discovered that differences in skin surface temperature in people providing truthful and deceptive answers depend on time segments of the recording and the type of test stimulus. This in turn proves that the reactions of a subject are related to the processing of information concerning a specific stimulus (question) and preparation to the answer. Interestingly, statistically significant measurements were acquired only in the case of the right half of the face. This can be explained by emotional reactions which the right hemisphere of the brain is responsible for or by the nervous activity conditioned by the sympathetic part of the autonomous nervous system aimed at immediate supply of oxygenated blood to the eyes. In the second experiment, procedures from the first were replicated but on a slightly larger sample (39 subjects with data from 24 examinations qualified to the final analysis), a different camera was used, and the system for tracing head movements was more sophisticated. Thanks to this, $91.7 \%$ of the subjects were correctly classified for truthfulness/deception. 
A similar experiment making use of the CIT procedure and detection of deception in utterances (false declarations concerning lack of knowledge about details of an event) in participants who perpetrated a mock crime (stealing a wallet) was conducted by K.K. Park, H.W. Suk, H. Hwang, and J-H. Lee. They analysed the readings from periorbital regions of the face (a triangle-shaped area between the eye and the nose on both sides of the nose, and also the area around the eyes). The study group was composed of 34 people. The examination made use of thermal imaging combined with analysis of variance (ANOVA). The participants were asked questions in accordance with the CIT procedure. According to this assumption, the person who stole the wallet will have critical knowledge of the subject. In the case of 'guilty' people answering irrelevant questions, a temperature of specific regions of the face recorded within 10 seconds from asking the question was by $0.55^{\circ} \mathrm{C}$ lower than in the case of answers provided to significant questions. In turn, in the 'innocent' participants, whose only task was to send an email from a laboratory, temperatures of specific fragments of the face while answering the significant questions were by $0.33^{\circ} \mathrm{C}$ lower as compared to irrelevant questions (Park et al. 2013).

Studies making use of an integrated measurement with the use of an infrared camera and polygraph were also conducted by K. Kim and J-H. Lee of Chung-Ang University in South Korea. The experiment made use of CQT (Comparison Questions Test). The study group were 37 people. Participants were divided into two subgroups. The first of them were supposed to steal a wallet from a computer lab and hide the evidence. The only task given to participants from the other subgroup was to send an email from the laboratory. Polygraph examination and examination making use of the infrared camera were made at the same time to develop and assess an integrated technique for observation and recording of physiological changes accompanying deception. Results analysis made it possible for the researchers to identify correctly $73.3 \%$ of participants in the study who answered deceptively the relevant questions (Kim, Lee 2014)

Are the changes in temperature of specific regions occurring in the face while lying related to brain activity (EEG)? The answer to this and other questions through thermal imaging was sought by U. Jain, B. Tan, and Q.P. Li. The scientists conducted an experiment in which the cohort of subjects was composed of 16 people. Some of them committed a mock crime (stealing a ring), and later all the subjects were to answer questions related to the circumstances of the committed theft. Before the start of the test, participants were divided into two subgroups. Every other one went to an electroencephalographic examination combined with ther- 
mal imaging. The other half of the group were asked questions in line with the CIT procedure (i.e. they were asked about details related with the mock crime). The analysis covered readings from the internal and external regions around the corners of the eyes, fragments of the nose, the tip of the nose, and the external corners of the mouth. Using the infrared, the researchers reached $83 \%$ of correct indications of deception. The error level was estimated at max. 0.485 , and min. 0.165 , which means that the lowest level of correct lie detection amounted to $51.5 \%$, and the highest to $83.5 \%$ (with 20 repetitions). In turn, EEG made it possible to achieve $90 \%$ of correct indications of deception in utterances (Jain et al. 2012).

An approach to thermography different than that of majority of researchers was demonstrated by P. Tsiamyrtzis, J. Dowdall, D. Shastri, I. Pavlidis, M.G. Frank, and P. Ekman. They recognised that what is needed is a solution that - with instrumental and automated detection of deception - would make it possible to develop conditions as close to real life as possible and ensured a statistically significant number of participants (a comparison of the fundamental assumptions present in various experiments with thermal imaging in nearly the last two decades is presented in Table 2). To achieve this, 39 people were randomly drawn from a population of 250 selected by M.G. Frank and P. Ekman. Each of them filled in a questionnaire involving biographic and personality questions. Later, the participants were grouped into twos, composed of people with opposing beliefs and views of the world. One person in each pair (the future subject) was informed that there is an envelope with a cheque in the hall. The task of the person was to find the envelope and to make a decision concerning its potential theft. The cheque was made to a group that the finder certainly did not support, which was to encourage the theft. Independent whether the theft occurred or not, the intended recipient of the cheque (or a supporter of the organisation that was to receive it) interrogated the subject. To strengthen the motivation of the experiment further, envisaged for the participants in the experiment were rewards (pecuniary) and punishments (in the form of money and doses of noise through headsets) were envisaged. Depending on whether one managed to convince the interrogator about one's innocence or not, and also on the correctness of the interrogator's opinion, various options of punishments and rewards for the people in a given pair and their groups were present. The questions used in the interrogations were designed by a team composed of experts in homicide, counterterrorism, and behaviourists. Most of the questions aimed at obtaining maximum number of non-verbal behaviours useful for analysing (Tsiamyrtzis et al. 2007). The questions were as follows:

1. Describe in detail everything you saw down the hall.

2. Describe your actions while you were down the hall. 
3. What was going through your mind regarding whether to take or leave the cheque?

4. Did you remove the cheque from the envelope?

5. Is there anything else you wish to tell me about the cheque or what you did?

6. Is everything you have told me about the cheque the truth?

7. What would you say if later I determined you lied to me about the cheque?

8. Where did you put the cheque?

9. What should happen to a person who took a cheque like this?

10. Have you ever told a lie to get out of serious trouble?

11. I know who that cheque was made out to. It is very understandable that you would not want to see money going to that organization. If I were in your shoes, I probably would have do anything in my power to avoid having money go to this organization. Now tell me the truth, did you take that cheque or not?

12. If you were to take a polygraph (lie detector machine) test, what do you think the results of this test would be?

13. Why do you think that someone would take this cheque?

The subjects provided free answers to the questions above, only once, and the interview was run at a natural speed. Later, the data recorded with an infrared camera were analysed. The top $10 \%$ of the hottest pixels in the periorbital region were selected and had average temperature, corresponding to the mean temperature of the vascular system in the internal corners of the eyes, calculated; and the recorded signal was filtered with a low-pass filter. The researchers noticed that various people react with different intensity to the same stressor. That is why they compared fluctuations of the temperature signal with the data from the entire interview with the subject in their calculations. If the deviation in the question-and-answer section area was greater than during the entire interview, the answer was considered deceptive, and if it was smaller - an opposite conclusion was drawn. Results close to 0 could be considered inconclusive. Altogether, a level of $87.2 \%$ correct indications was reached. 
Table 2. Thermal vision in detection of deception: a summary of selected experiments

\begin{tabular}{|c|c|c|c|}
\hline Authors & $\begin{array}{l}\text { Type of subject behaviour } \\
\text { in the experiment }\end{array}$ & $\begin{array}{l}\text { Region of interest } \\
\text { (ROI) in the face }\end{array}$ & $\begin{array}{l}\text { Diagnostic } \\
\text { value } \\
\text { of the } \\
\text { method } \\
\text { applied }\end{array}$ \\
\hline $\begin{array}{l}\text { I. Pavlidis, } \\
\text { J. Levine, } \\
2001\end{array}$ & $\begin{array}{l}\text { The subjects supposed to lie in the test were } \\
\text { to jab a mannequin with a screwdriver and } \\
\text { steal money }(\$ 20) \text {. The task of the innocent } \\
\text { subjects, unconnected to the event, was to } \\
\text { answer truthfully. }\end{array}$ & $\begin{array}{l}\text { the forehead, } \\
\text { and primarily the } \\
\text { periorbital region }\end{array}$ & $78 \%$ \\
\hline $\begin{array}{l}\text { D.A. Pollina } \\
\text { et al., 2004; } \\
\text { D.A. Pollina } \\
\text { et al., } 2006\end{array}$ & $\begin{array}{l}\text { The task of the subjects supposed to lie } \\
\text { in the test was to jab a mannequin with } \\
\text { a screwdriver and steal money. The task } \\
\text { of the innocent subjects was to answer } \\
\text { truthfully. }\end{array}$ & $\begin{array}{l}14 \text { regions in the } \\
\text { face, around the } \\
\text { mouth, eyes, nose, } \\
\text { and neck; mainly } \\
\text { the } \\
\text { periorbital region }\end{array}$ & $91.7 \%$ \\
\hline $\begin{array}{l}\text { P. Tsiamyrtzis } \\
\text { et al., } 2006 \\
\\
\end{array}$ & $\begin{array}{l}\text { Discovery of an envelope with a cheque, } \\
\text { its optional theft, and later participation } \\
\text { in an interrogation. The selection of the } \\
\text { potential thief and interviewer (beneficiary } \\
\text { of the cheque) was based on opposing traits } \\
\text { of personality and different views of the } \\
\text { world. Moreover, an extended system of } \\
\text { motivation was used. }\end{array}$ & periorbital region & $87.2 \%$ \\
\hline $\begin{array}{l}\text { Z. Zhu } \\
\text { et al., } 2007\end{array}$ & no data & $\begin{array}{l}\text { the forehead } \\
\text { (supraorbital } \\
\text { region) }\end{array}$ & $76.3 \%$ \\
\hline $\begin{array}{l}\text { D. Shastri } \\
\text { et al., } 2008\end{array}$ & no data & $\begin{array}{l}\text { periorbital region } \\
\text { (internal corners of } \\
\text { the eyes) }\end{array}$ & $82 \%$ \\
\hline $\begin{array}{l}\text { L. Warmelink } \\
\text { et al., } 2010 .\end{array}$ & $\begin{array}{l}\text { The subjects invited to experiments in the } \\
\text { airport were to answer truthfully about the } \\
\text { destination of their travel but had to lie } \\
\text { about the reasons why they travel. }\end{array}$ & no data & $64-69 \%$ \\
\hline $\begin{array}{l}\text { E. Salazar } \\
\text { Lopez } \\
\text { et al., } 2012 \\
\end{array}$ & $\begin{array}{l}\text { The subjects were given the task of making } \\
\text { a fictional alibi and lie about the course of } \\
\text { the day in a telephone interview. }\end{array}$ & $\begin{array}{l}\text { the area around the } \\
\text { nose, corners of the } \\
\text { eyes }\end{array}$ & \\
\hline $\begin{array}{l}\text { U. Jain } \\
\text { et al., } 2012\end{array}$ & $\begin{array}{l}\text { The subjects were to steal a ring and later lie } \\
\text { about the mock crime. }\end{array}$ & $\begin{array}{l}\text { corners of the } \\
\text { eyes (internal and } \\
\text { external), nostrils } \\
\text { (external edges), } \\
\text { nose and corners of } \\
\text { the mouth }\end{array}$ & $83.5 \%$ \\
\hline
\end{tabular}




\begin{tabular}{|l|l|l|c|}
\hline $\begin{array}{l}\text { K.K. Park } \\
\text { et al., } 2013\end{array}$ & $\begin{array}{l}\text { The subjects who were to lie in the test were } \\
\text { to steal a wallet. The task of the subjects } \\
\text { who were to tell the truth was to send an } \\
\text { email from the lab. }\end{array}$ & $\begin{array}{l}\text { the triangle-shaped } \\
\text { area between the } \\
\text { eye and the nose, } \\
\text { on both sides of the } \\
\text { nose; also around } \\
\text { the eyes (principal) }\end{array}$ & $98.89 \%$ \\
\hline $\begin{array}{l}\text { K. Kim } \\
\text { et al., } 2014\end{array}$ & $\begin{array}{l}\text { The subjects who were to lie in the test were } \\
\text { to steal a wallet. The task of the subjects } \\
\text { who were to tell the truth was to send an } \\
\text { email from the lab. }\end{array}$ & no data & $\begin{array}{l}70.6 \%- \\
73.3 \%\end{array}$ \\
\hline $\begin{array}{l}\text { B.A. Rajoub, } \\
\text { R. Zwiggelaar, } \\
\text { 2014. }\end{array}$ & $\begin{array}{l}\text { The subjects were to learn a false personal } \\
\text { profile with data about their education, } \\
\text { family, and job. Subsequently, they were } \\
\text { supposed to lie during an interview about } \\
\text { who they are and what they do in their } \\
\text { lives. }\end{array}$ & $\begin{array}{l}\text { corners of the eyes } \\
\text { (by the nose) }- \\
17 x 17 \text { pixels. }\end{array}$ & $87 \%$ \\
\hline
\end{tabular}

Source: own materials or the authors

D. Shastri, P. Tsiamyrtzis, and I. Pavlidis noticed that the heuristic method of selecting $10 \%$ of highest temperature pixels is strongly dependent on the qualifications of the camera operator and selection of the preliminary region of interest (Shastri et al. 2008). Instead, they presented a new method for precise distinction of the signal from the periorbital region. In the first stage, the area is segmented, and in the second - it is tracked frame by frame, while the third contains the refinement of the heat signal from unnecessary interferences. Segmentation is effected through the choice of two points situated in the internal corners of the eyes in the starting frame, and localisation of pixels with highest temperature, which are later used in an adaptive fuzzy connectedness algorithm. It was assumed that if the physiological change accompanying the critical question will be greater than the change in the base line, the subject's answer will be considered deceptive. Otherwise, the subject is classified as telling the truth. In experiments involving 39 subjects, deceptive answers were correctly discovered in $82 \%$ of the cases.

In their experiments most researchers focused on the periorbital region of the face, yet there were also other attempts, for example, thermal imaging of the nose region. The neurophysical reactions caused by stress that appear in the region are manifested through short-term increased sweating (Shastri et al. 2012). In turn, Z. Zhu, P. Tsiamyrtzis, and I. Pavlidis discovered that the muscle responsible for wrinkling the forehead is more active than usually when a subject experiences persistent stress (Zhu et al. 2007). The signal from the periorbital region provides information concerning momentary stress related to alarming stimuli, while the signal from the supraorbital region accounts for information concerning long-term stress resulting from mental 
involvement. These allowed to put up a hypothesis that deceptive individuals can be more strongly involved mentally, because they make up various stories. Thirty people were invited to the test. It was discovered the temperature changes during the interrogation result from two phenomena: the interrogation itself, and lying. In the case of deceptive individuals, the two factors become superimposed. The rate of correct detection of deception based on facial temperature changes around the forehead amounted to $76.3 \%$.

\section{Polish experience}

Although the theoretical possibility of using thermal vision cameras in detection of deception was recognised in Poland already in the 1970s (Kołecki 1979), the subject was discontinued for many years. Only recently, the interest in the method increased, which resulted in the first experimental attempts at using an infrared camera for that purpose. The experiments conducted so far (initial investigations by Polakowski, Kastek, Pilski 2011; Staszel, Wojtarowicz, Zając 2013), have not gone beyond the general support for a well-known fact that an infrared camera can record facial temperature changes as physiological correlates of emotions. Moreover, they validated problems resulting from the need to stabilise the head of the subject for the time of the examination put forth by other authors.

\section{Problems in infrared studies conducted so far}

Some researchers emphasise that thermal changes in specific regions of the face result not only from the subject being deceptive, but may correlate with the activity of specific groups of facial muscles, metabolism, sicknesses, and ambient heat emission (Pollina et al. 2004; Warmelink et al. 2010; Rajoub et al. 2014). Others point to the need for standardisation of the research method, technique, and high resolution equipment. It is necessary to develop more advanced methods (algorithms) for tracking the face, and also to develop a simpler, faster, and more precise way of conducting analyses of the collected thermal data (Park et al. 2013). Moreover, a more decided approach to the statistical analysis of maximum thermal values is emphasised: the analysis would focus not on a single pixel but on a pixel array from thermal images (Park et al. 2013).

Depending on the region of the face which is our region of interest, seemingly simple obstacles emerge and render precise measurements practically impossible. Such obstacles include e.g. spectacles, as glass may conduct neither far- nor mid-wavelength infrared, in the consequence distorting the records concerning temperature changes 
around the eyes. A long and thick fringe in turn interferes with measurements of forehead temperature.

A major problem while recording changes taking place in specific regions of the face are also the movements of the subject's head. It is necessary to limit the movements of the subject to minimum while performing point imaging. Steps aimed at limiting the instabilities in data recording caused by the subject's movement were taken. An experiment aimed at testing system efficiency - a network for tracing temperature changes in specific fragments of the face - was conducted among others by D. Shastri, P. Tsiamyrtzis, and I Pavlidis. Their study proved that a network system for tracing temperature changes provides highly constant efficiency (20 trials), with an average precision error of one pixel. Efficiency of monitoring network is decidedly greater than that of a single tracker while the subject is moving the head. To optimise the interaction of each individual tracker, John von Neumann's Game Theory was used. The adaptation of the theory aimed at observation of individual trackers as players in a game, whose goal was to increase the impact of an individual tracker by building coalitions with other trackers to achieve a common goal. The results of the study proved that a system for network tracking has a greater efficiency than a single tracker (Shastri et al. 2008).

The goal behind the creation of a more perfect system for tracking temperature changes of specific regions of the face was set up by P. Tsiamyrtzis, J. Dowdall, D. Shastri, I. Pavlidis, M.G. Frank, and P. Ekman. The need was justified by the fact that even a momentary loss of the tracking path results in sudden leaps in the recorded temperature signal, which in such a case no longer reflects true reactions (Tsiamyrtzis et al. 2007). The scientists designed a so-called tandem tracking system, which is expected among others to be more resilient to head movements of the subject. It is a modified system for tracking a single (periorbital) region using information from another (central) region. A technique for adjusting the pattern based on the selection of the object of interest in the initial frame and later finding regions most akin to the original pattern in the following frames was used. This innovation helps to reduce errors in face tracking construed as any diversion of the point of tracking from the periorbital region for a period extending one frame. In this way, the recording of temperature changes in time became more adequate and legible (see: Fig. 4). The tracking system retains capacity to recover in the cases of occlusion incidents and turns up good results (accuracy of up to \pm 2 pixels compared to the actual target), the translational speed was $\leq 3$ pixels per frame, and rotational speed was $\omega \leq 5$ radians per frame. This luckily corresponded to the actual subject dynamics. 
Fig. 4. A comparison of obtained temperature signals from the periorbital region of a subject (without tracking and with tandem tracking) in time.

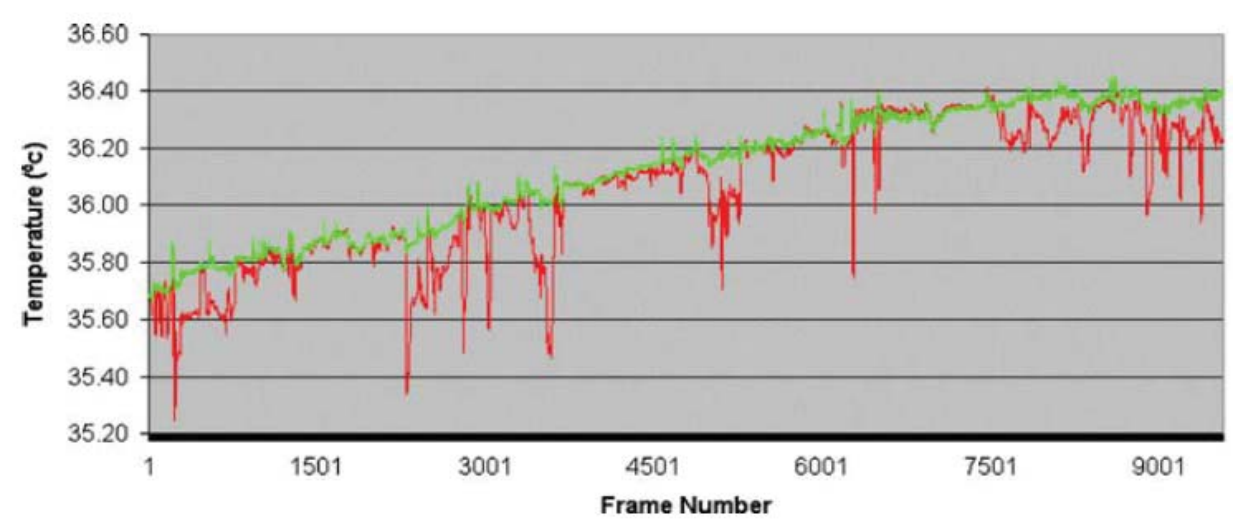

No Tracking

Tandem Assisted Tracking

Source: P. Tsiamyrtzis P., J. Dowdall, D. Shastri, I. Pavlidis, M.G. Frank, P. Ekman (2007), Imaging facial physiology for the detection of deceit, International Journal of Computer Vision, Vol. 71, p. 199.

As far as the technological aspects for detection of deception through combining a polygraph examination with thermography are concerned, computer software processing all the recorded data in real-time and making it presentable in a single polygraph chart would be handy.

Despite pointing to the still existing limitations of various kind that impact the precision of the method and its practical applicability, most researchers who participated in the thermal vision experiments perceive a vast potential in the method. Not all, however, approach this type of examinations with enthusiasm, which is especially true of the use of an infrared camera as a tool for routine control of integrity. For example, a group of experts specialising mostly in non-instrumental methods of deception detection (including A. Vrij) believe that thermal imaging will lead to an excessive number of false cases of detection of deception, because there are various sources of anxiety, and no significant changes between the truthful and lying individuals are observed before embarking on the interview (Warmelink et al. 2010). As far as an infrared camera can be taken considered in mass security checks, for example, in airports, this makes sense only during an interview and not remotely, and even more so without making the subject aware. Moreover, in the experiments they conducted, people running interviews who did not account for the recording 
from infrared cameras formed more accurate opinions. That is why researchers suggest that it is better to invest funds into the enhancement of interviewing methods rather than into upgrading thermal imaging equipment.

\section{Conclusions}

It seems to go without saying that the method for thermal registration of facial temperature changes as a correlate of emotions is interesting for psychology, psychophysiology, and neuropsychology (Milan et al. 2012). Moreover it becomes highly promising in the detection of deception and hidden information (Jain et al. 2012).

As the experiments conducted so far show, the best results are obtained when the method is combined with classical polygraph examinations (Pollina et al. 2004; Kim et al. 2014). At the current stage of research, this is however not yet a solution that could be used efficiently as an independent method for detecting deception. Besides minor obstacles of technical nature, which can be eliminated gradually in the successive experimental studies, application of this method for the detection of deception has as yet not been possible in practice, especially on a mass scale, without the awareness and cooperation on behalf of the subject. Secondly, an examination of facial temperature changes as an independent method of deception detection would be based on the assessment of only a single physiological coordinate of emotions (moreover: being secondary to the changes in the circulatory system and muscle tension), while a classical polygraph examination is based on a simultaneous assessment of at least three such correlates.

The future of this method of lie detection may be perceived in a) treating it as supplementation of a classical polygraph examination providing another emotion coefficient subjected to assessment (facial temperature changes - mostly in periorbital region); b) using it in conjunction with other methods that allow contact-free (i.e. remote) observation of at least two other physiological indicators (emotion correlates) - e.g. changes in the vice, eyeball movements, etc. This, however, is a task by far more difficult.

\section{References}

Bauer J., Dereń E. (2014), Standaryzacja badań termograficznych w medycynie i fizykoterapii, Acta Bio-Optica et Informatica Medica Inżynieria Biomedyczna, Vol. 20, No. 1, p. 12. 
Eysenck H.J. (1971), Sens i nonsens w psychologii, Warszawa, pp. 87-88.

Hilgard E.R. (1972), Wprowadzenie do psychologii, Warszawa, pp. 243-245.

Jain U., Tan B., Li Q. (2012), Concealed Knowledge Identification using facial thermal imaging, Li Creative Technologies, Florham Park, NJ, USA.

Kim K., Lee J-H. (2014), Detecting deception using integrated thermal imaging and polygraph, International Journal of Psychophysiology, Vol. 94.

Kołecki H. (1979), Kryminalistyczne zastosowania termografi, Warszawa.

Levine J., Pavlidis I, Cooper M. (2001), The face of fear, The Lancet, Vol. 357, No. 9270.

Memarian N., Venetsanopoulos A.N., Chau T. (2009), Infrared thermography as an access pathway for individuals with severe motor impairments [online], Journal of Neuroenigineering and Rehabilitation, Vol. 6, No. 11, [accessed on: 27.03.2015], www. jneuroengrehab.com/content/pdf/1743-0003-6-11.pdf.

Park K.K., Won Suk H., Hwang H., Lee J-H. (2013), A functional analysis of deception detection of a mock crime using infrared thermal imaging and the Concealed Information Test, Frontiers in Human Neuroscience, Vol. 7.

Pavlidis I., Eberhardt N.L., Levine J.A. (2002), Seeing through the face of deception, Nature, Vol. 415, p. 35.

Pavlidis I, Levine J.A. (2001), Monitoring of periorbital blood flow rate through thermal image analysis and its application to polygraph testing [online], Proceedings of the 23rd Annual EMBS International Conference, 25-28.10.2001, Istanbul, Turkey, [accessed on: 03.04.2015], www.cpl.uh.edu/publication_files/C17.pdf.

Pavlidis I, Levine J. (2002a), Thermal Facial Screening for Deception Detection, Proceedings of the Second Joint EMBS/BMES Conference, Houston, TX, USA, 23-26.12 .2002 .

Pavlidis I, Levine J. (2002b), Thermal Image Analysis for Polygraph Testing, IEEE Engineering in Medicine and Biology, Vol. 21, No. 6, pp. 56-64.

Pavlidis I,. Levine J.A., Baukol P. (2000), Thermal imaging for anxiety detection, Proceedings 2000 IEEE Workshop on Computer Vision Beyond the Visible Spectrum: Methods and Applications, Hilton Head Island, SC, 16.06.2000, pp. 104-109.

Polakowski H., Kastek M., Pilski J. (2011), Analysis of facial skin temperature changes in aquaintance Comparison Question Test, European Polygraph, Vol. 5, No. 3-4 (17-18), pp. 107-121. 
Pollina D.A., Ryan A.H. (2004), The relationship between facial skin surface temperature reactivity and traditional polygraph measures used in the psychophysiological detection of deception: a preliminary investigation, Polygraph, Vol. 33, No. 3.

Pollina D.A., Dollins A.B., Senter S.M., Brown T.E., Pavlidis I., Levine J.A., Ryan A.H. (2006), Facial Skin Surface Temperature Changes During a "Concealed Information” Test, Annals of Biomedical Engineering, Vol. 34, No. 7, pp. 1182-1189.

Rajoub B.A., Zwiggelarr R. (2014), Thermal Facial Analysis for Deception Detection, IEEE Transactions on Information Forensics and Security, Vol. 9, No. 6, p. 1015-1023 .

Salazar Lopez E., Dominguez E., de la Fuente J.M., Meins A., Iborra O., RodriguezArtacho M.A., Gomez Milan E. (2012), The mental nose: thermography and the Pinocchio effect, University of Granada, Spain.

Shastri D., Merla A., Tsiamyrtzis P., Pavlidis I. (2009), Imaging Facial Signs of Neurophysiological Responses, IEEE Transactions on Biomedical Engineering, Vol. 56, No. 2.

Shastri D., Papadakis M., Tsiamyrtzis P., Bass B., Pavlidis I. (2012), IEEE Transactions on Affective Computing, Vol. 3, No. 3.

Shastri D., Tsiamyrtzis P., Pavlidis I. (2008), Periorbital Thermal Signal Extraction and Applications, 30th Annual International IEEE EMBS Conference, Vancouver, British Columbia, Canada, 22-24.08.2008.

Staszel R., Wojtarowicz M., Zając P. (2013), Praktyczne możliwości zastosowania kamery termowizyjnej, Studia Prawnicze. Rozprawy i Materiały, 2 (13), pp. 109-120.

Trovillio P.V. (1938/1939), A history of lie-detection, The Journal of Criminal Law and Criminology, Vol. 29, No 6, p. 849.

Tsiamyrtzis P., Dowdall J., Shastri D., Pavlidis I., Frank M.G., Ekman P. (2007), Imaging facial physiology for the detection of deceit, International Journal of Computer Vision, Vol. 71, pp. 197-214.

Zhu Z., Tsiamyrtzis P., Pavlidis I. (2007), Forehead Thermal Signature Extraction in Lie Detection, Proceedings of the 29th Annual International Conference of the IEEE EMBS Cité Internationale, Lyon, France, 23-26.08.2007. 